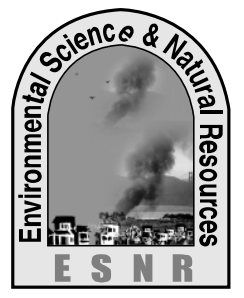

\title{
Impact of SIDR on Crops, livestock and Fisheries in Some Selected Villages of Pirojpur District of Bangladesh
}

\author{
F. R. Moni, M. S. Hossen, A. Sultana, M. S. Rumi, B. S. Nahar and M. A. Baten
}

Department of Environmental Science, Bangladesh Agricultural University,Mymensingh-2202

\begin{abstract}
SIDR had great impact on crop, livestock and fisheries at Pirojpur district in Barisal Division. To perform this study data were collected from the three selected village (south Shailkati, Hothkhali and Lahori) affected people by random sampling after selecting the study topic and area. SIDR also created a great impact on the production of different types of crop. Rice production was reduced to $7.5 \%$, chili to $11.66 \%$ and vegetables to $10 \%$. After SIDR the production of pulse was increased $21.67 \%$ due to increase in acreage in Pirojpur. From this study we found vegetables lands (58.33\%) and fish in river (70.83\%) were affected by the saline water than the rice $(33.33 \%)$, fruit $(9.16 \%)$ and fish in pond $(24.16 \%)$ respectively. Due to the tidal surge and storm the cattle reduced to $18 \%$, goats to $14 \%$, buffalos to $21 \%$, chickens to $10.09 \%$, duck to $8.82 \%$, Pigeons to $24 \%$; that means majority of the poultry birds were reduced than the livestock. The food habit of the affected people was also changed. They now took more flour rather than rice. The scarcity of agricultural production created the reduction of food stock. Most of the respondents had no food stock. But the situation is better than close post SIDR period. Most of the cases they are adopting with the changing socio-economic conditions.
\end{abstract}

Key wards: Agricultural Production, Crops, Livestock, Fisheries, SIDR

\section{Introduction}

Bangladesh often suffers from many climate induced disasters such as flood, drought, and cyclone. Among those natural hazards, cyclone is a tropical storm or atmospheric turbulence involving circular motion of winds, occurs in Bangladesh almost every year. About one tenth of the global tropical cyclone occurs in the Bay of Bengal (GOB, UNDP, World Bank, 1993). On 15 November 2007, Cyclone SIDR struck the south-west coast of Bangladesh with winds up to 240 kilometers per hour (Banglapedia, 2008).

The cyclone severely ravaged four districts of Barguna, Bagerhat, Patuakhali, and Pirojpur, and badly damaged another eight districts. According to official estimates nearly two million households with 8.7 million people were affected, 1.5 million houses damaged, 4.1 million trees destroyed, and crops in one million hectares of land were fully or partially lost (Shibayama., 2008). The damage and loss assessment for crops, livestock, and fisheries was estimated to be BDT 30.2 billion (US\$ 437.6 million), of which BDT 1.5 billion (US\$ 21.3 million) was damage to assets and BDT 28.7 billion (US\$ 416.3 million) was production loss (GoB 2008). Rice production was heavily affected. The cyclone struck right before harvesting time and farmers have incurred losses. According to the latest GoB estimates between 800,000 to 1.3 million MTs of paddy has been destroyed. Most of the damage in the livestock sub-sector was caused by the tidal surge that drowned animals and birds and by falling trees Almost 80 percent of the animals and 76 percent of the birds died in the four worst affected districts. The estimated value of damage to the livestock sub-sector is BDT
1.3 billion (US\$ 19.33 million). The damage and loss that SIDR caused consists of damage to the fisheries infrastructure and losses in catch or production. Damage and losses in the fisheries sub-sector, in the ten most affected districts, are estimated at BDT 463 million (US\$ 6.7 million). According to Bangladesh Frozen Food Exporters' Association, the country's shrimp or frozen food industry fears an estimated loss of Tk 250 crore. After SIDR the problem became severe and made barrier to agriculture. The root cause behind this is that tidal water increases the salt portion of the soil which indeed decreases its fertility. Therefore, the great changes were observed in their crop, livestock and fisheries production as well as their daily life. The present study will investigate the post SIDR scenario of Crops, livestock and Fisheries in Some Selected Villages of Pirojpur District of Bangladesh with the following objectives-

1. To find out the impact of saline water on crops and fishes production.

2. To find out the impact of SIDR on livestock.

3. To find out the impact of SIDR on sources of rice for consumption, food habit and food stock.

\section{Methodology}

\section{Selection of the study area}

The study area is located beside the river Balasher in the south-western coastal region of Bangladesh that is more affected area and the south and south-western districts have suffered heavy loss in vegetables, crops (rice) and houses. The damages were estimated in three villages South Shailkathi, Hothkhali and Lahori under the upazilla of Bhandaria, Pirojpur Sadar and Mothbaria under Pirojpur district respectively. 


\section{Preparation of interview schedule}

Interview schedule was prepared with different parameter such as farmer's name, occupation, level of education, family size, age, farm size, changes in production of crop, damages in crop, impact on food habit, changes in food habits due to SIDR of the respondents before and after SIDR, duration of sufficient household food stocks, food shortage problem \& meet the food demand during disaster, sources of rice for eats and how they are adapted with this natural disaster.

\section{Sample size determination}

The large group of individuals is known as population and the subset is known as the sample. The sample design refers to the techniques or procedures, the researcher would adopt in selecting items for the sample. At first I collected $40 \mathrm{Sidr}$ affected people list from SAAO from each village's i.e total 240 people who are related with crop by different way. Then I took $40 \%$ people from from each village by random sampling and the total respondent number was 120 .

\section{Collection of data}

This study was mainly based on primary data. Secondary data were will be collected to supplement primary data.

\section{Primary data collection}

Primary data was collected through a structured interview schedule. A interview schedule survey was conducted through a direct field survey to collect the required data. In this process, the respondents were requested to answer the questions, carefully and honestly, regarding their socio-economic condition and the extent and problems of involvement in economic activities.

\section{Secondary data collection}

Data were collected from relevant books and journals, articles of different writers, seminar, thesis papers and Internet, different agencies.

\section{Collection of secondary materials}

To supplement primary data collection, relevant secondary data will be a crying need.

\section{Data processing and interpretation}

A survey with interview schedule was conducted to gather information from both primary and secondary sources. Then that data were processed and analyzed through using different statistical tools like pie-chart, bar-diagram, table etc. Several computer based software e.g. Microsoft excel; SPSS were used for processing data. After that necessary text document was included for the report.

\section{Analysis of collected data}

Different analytical tools have been applied for this study. Descriptive analyses explain by the analytical tools were SPSS, MS Excel are the required programs. Analysis shown by the charts and graphs perform by the Ms Excel. Data recording and encoding have been for measuring relationship of various indicators with the programs SPSS, Ms Excel.

\section{Results and Discussion}

\section{Assessment the changes in crop production due to SIDR}

The tidal surge created a significant impact on the production of different crops like rice, chili, pulse, vegetables, betel nut and coconut. This study found that the production of rice $(7.5 \%)$, chili $(11.66 \%)$, and vegetables $(10 \%)$ was reduced due to saline water entry into the crop field after SIDR. But the production of pulse was found to increase $21.67 \%$ in Fig. 1. It was due to increase in acreage in Pirojpur.

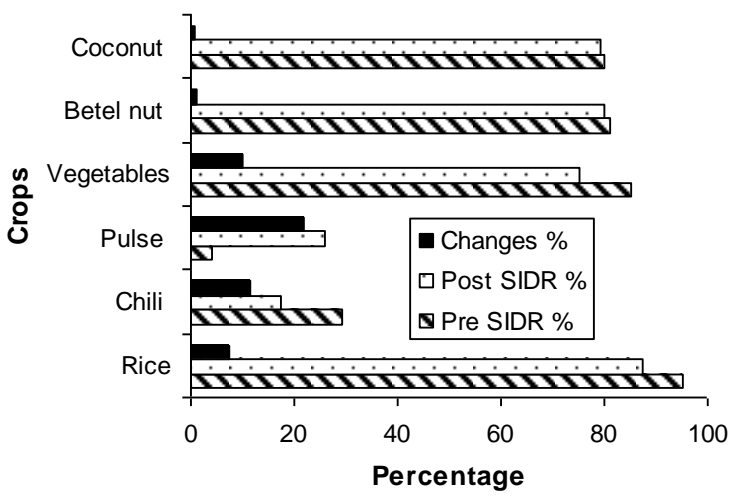

Fig. 1: Changes in production of crops due to SIDR

\section{Assessment damage of livestock}

Livestock plays a significant role for the rurc landless and for marginal economy and small farmers. Raising livestock was not only labor intensive, providing many employment opportunities, but also generated regular monthly income from the sale of milk, eggs, poultry, and goats. Most of the damage in the livestock sub sector was caused by the tidal surge. Table 1 shows the report on the damaged of livestock during SIDR. Table 1. Clearly showed that during the post-SIDR, the cattle were reduced to $18 \%$, goats to $14 \%$, buffalos to $21 \%$, chickens to $10.09 \%$, duck to $8.82 \%$, Pigeons to $24 \%$; that means majority of poultry were reduced than the livestock. The baseline survey found that due to SIDR cow and bullock loss was $30 \%$, buffalo $15 \%$ goats, $15 \%$ and chicken and duck $85 \%$ are being damaged (Biswas, 2011). 
Table 1. Damage of livestock

\begin{tabular}{|l|l|l|l|}
\hline Name of livestock and poultry & Total pre-SIDR & Total post-SIDR & Reduced (\%) \\
\hline Cow & 294 & 242 & 18 \\
\hline Goat & 237 & 202 & 14 \\
\hline Buffalo & 112 & 89 & 21 \\
\hline Chicken & 1218 & 426 & 10.09 \\
\hline Duck & 306 & 279 & 8.82 \\
\hline Pigeon & 50 & 38 & 24 \\
\hline
\end{tabular}

Assessment of the impact of saline water on crop and fishes production

During SIDR saline water damaged the crop plant and fishes due to damage of the embankment in the study area. From this study we found that rice, vegetables, fruit, fish in both pond and river were significantly affected by water salinity. Vegetables land (58.33\%) and fish in river $(70.83 \%)$ were more affected than rice $(33.33 \%)$, fruit $(9.16 \%)$ and fish in pond $(24.16 \%)$, respectively. The respondent also explained that the fish in the river was dramatically

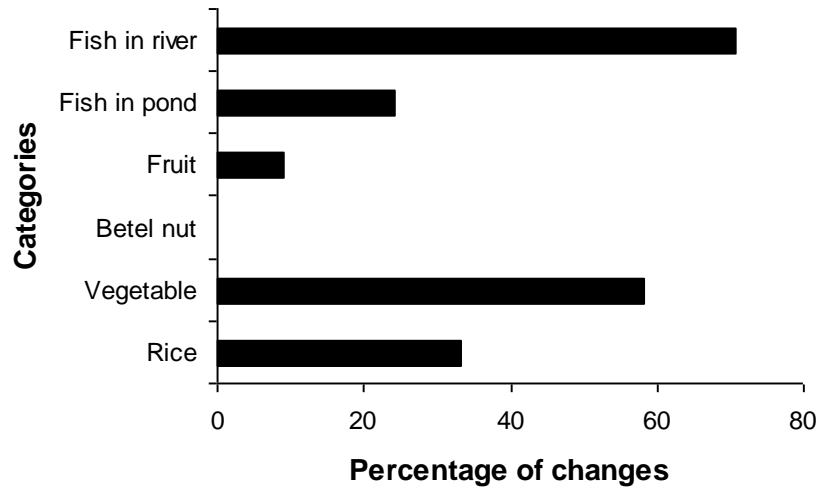

reduced after SIDR and several types of fish are not found at present in the river in Fig. 2.

Assessment of sources of rice for consumption during the post SIDR period

After the SIDR the production of own rice source was reduced to $9.5 \%$. About $21.68 \%$ of the respondent had to buy rice from the market and it was found to increase $1.84 \%$ from the pre-SIDR and about $45.66 \%$ of the respondent had to both own production and buy rice from the market and it was found to also increase $38.33 \%$ from the pre-SIDR time in Fig. 3.

Fig. 2. Impact of saline water on crop and fishes production 


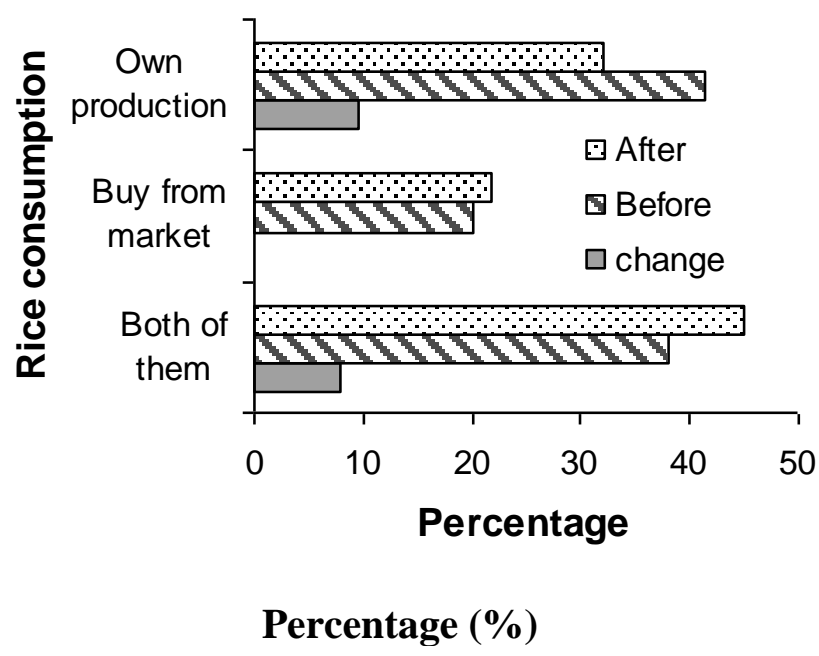

Fig. 3. Sources of rice during pre and post SIDR period

Assessment of the changes of food habit due to SIDR

From the study it was observed that the respondents gradually reduced to their habit of taking rice (7\%), fish (10.83\%), fruits (6.67\%), eggs (5.83\%), vegetables $(5 \%)$, meat (1\%) But they took more flour (34.34\%) than the pre SIDR in Fig. 4.

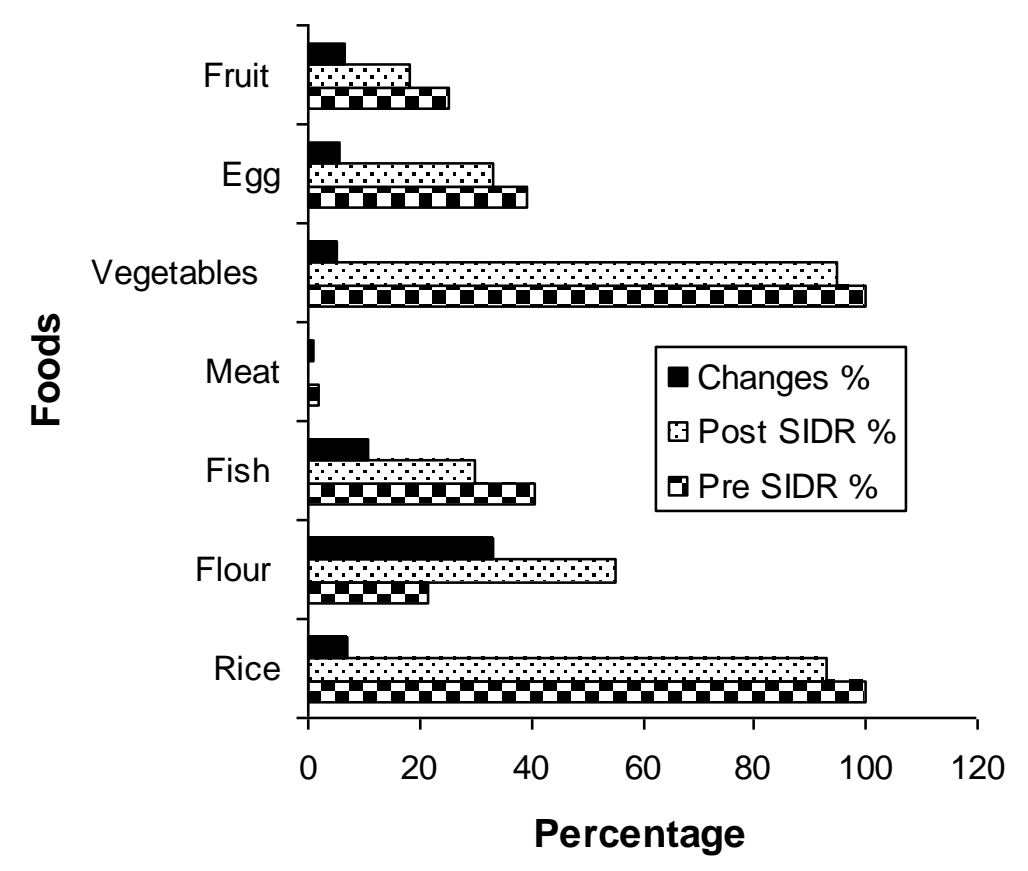

Fig. 4. Changes of food habit due to SIDR

Assessment of the food stock in the households during the post SIDR period

This study found that $77.33 \%$ of the respondents had no food stock for future, $7.66 \%$ of them had less than 2 weeks food stock, $3.33 \%$ of the respondents had 2 weeks to 1 month food stock, $1.68 \%$ of them had 1-3 months food stock and another $10 \%$ had more than 3 months food stock. Due to low average household income and the employment opportunity and also for 
the reducing production of crop most of the respondent had no food stock in Fig 5.

It is estimated that about 2 million persons have lost income and employment in the more affected Districts, and that they have seen their income for this year reduced to about a third of the average (Biswas, 2011

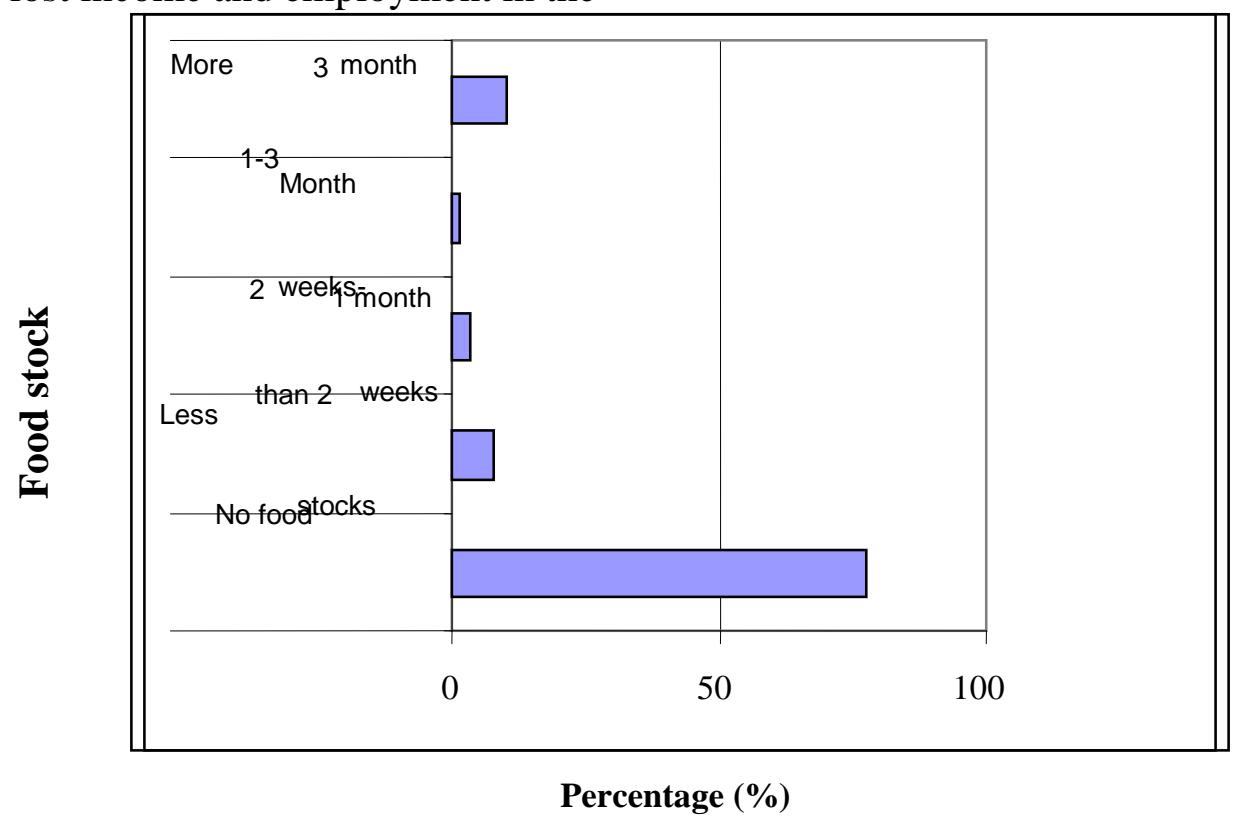

Fig. 5. Status of food stock during the post SIDR period

\section{Conclusion}

This research was conducted on the field survey basis in three selected villages of Pirojpur district in Bangladesh to gather the information of the impact of SIDR on crop, livestock, fisheries. After SIDR due to damage of embankments, saline water was flooded the cropland and fishes. We found vegetables land $(58.33 \%)$ and fish in river $(70.33 \%)$ were more affected than the rice land (33.33\%), fish in pond and fruit $(9.16 \%)$. This study found that $77.33 \%$ of the respondents had no food stock for future, $7.66 \%$ of them had less than 2 weeks food stock, $3.33 \%$ of the respondents had 2 weeks to 1 month food stock, $1.68 \%$ of them had 1-3 months food stock and another $10 \%$ had more than 3 months food stock. After the SIDR majority (39.16\%) of the respondent collected household use water from river than the pond $(35 \%)$ and the tube well $(25.84 \%)$. After SIDR majority of the respondents were suffering with dysentery (74.5\%) than diarrhea (27.5\%).

\section{References}

Banglapedia. 2008. at http:// banglapedia. search.com.bd/HT/C_0397.htm

Biswas, R.C. 2011. Post cyclone rehabilitation of agriculture in the sidr affected areas in south west Bangladesh. A Dissertation for the Degree of Master in Disaster Management. BRAC University, Dhaka, Bangladesh.

GOB, UNDP, World Bank. 1993. Multipurpose cyclone Shelter Programme. Executive Summary of Final Report.

Government of Bangladesh. 2008, Cyclone Sidr in Bangladesh Damage, Loss, and Needs Assessment for Disaster Recovery and Reconstruction Supported by European Commission. 